\title{
Iron-nickel oxyhydroxide catalyst from Watts bath for the oxygen evolution reaction in
} water electrolysis

Dario Delgado*, Jan Bucher

Department of Chemistry and Biochemistry, University of Bern, Bern, Switzerland

\begin{abstract}
A hydrogen economy is necessary to meet the social demands for less consumption of fossil fuels and it has several barriers that need to be addressed if this technology is to become cost effective. The oxygen evolution reaction (OER) is one of these barriers and catalysts based on nickel oxyhydroxide (NiOx) are believed to be promising for alkaline OER. We report results of iron doping for $\mathrm{NiOx}$, we synthesized by electrodeposition, combinations of iron in Ni Watts solution to develop Fe- NiOx catalysts. The best sample has an overpotential of $254 \mathrm{mV}$ at 10 $\mathrm{mA} \mathrm{cm}{ }^{-2}$, this result is competitive to the best results found for alkaline OER. Our methodology consists of: linear and cyclic voltammetry, galvanostatic stability and electrochemical impedance spectroscopy as electrochemical techniques. In addition, physical catalyst characterization techniques include: scanning electron microscopy equipped with energy-dispersive X-ray spectroscopy, Raman spectroscopy and surface elemental analysis by wet chemistry.
\end{abstract}

Keywords: nickel oxyhydroxide, oxygen evolution, iron dopant, water electrolysis catalyst.

\section{*Email: dario.delgado@hotmail.com}




\section{Introduction}

A hydrogen economy is gaining traction in major economies, in this respect, European cities such as Paris, Copenhagen and Oxford are banning petrol and diesel cars $^{1,2}$. The main source of smog and greenhouse gases is transport, specifically combustion engine vehicles. Nonpolluting vehicles are being considered as a substitute by local governments to promote zeroemission zones. Vehicles which could potentially be adopted are fuel cell and electric ones in these zones, and fuel cell vehicles are powered by hydrogen.

Hydrogen for the transportation sector still has barriers that make it impracticable. For example, storing hydrogen is expensive, however, recent developments in membrane technology converts stored hydrogen in ammonia into hydrogen, ready to be used in fuel cell vehicles ${ }^{3}$. In addition, the cost of production of hydrogen could be lowered as photovoltaic technology (PV) becomes less costly ${ }^{4}$, when PV is used to power water electrolysis to generate hydrogen. Another barrier of interest is the energy consumed in water electrolysis by the oxygen evolution reaction (OER) to generate hydrogen. This is a well-known barrier in the electrochemical community and efforts to make it more efficient by improving the overpotential $(\eta)$ of the OER are being done $\mathrm{e}^{5,6}$. In this respect, nickel oxyhydroxide $(\mathrm{NiOx})^{7-13}$ has been introduced as a potential catalyst for the OER in alkaline media. This material has the advantage of being earth abundant, in addition of being active towards the OER. This material has weaknesses, the Bode scheme ${ }^{14}$ shows that $\mathrm{NiOx}$ at overcharge or working at high overpotentials, becomes inactive for the OER as there is a phase transition from beta to gamma (gamma considered to be OER inefficient). In addition, bimetallic combinations of $\mathrm{NiOx}$, as for instance $\mathrm{FeNiOx}$, are unstable as iron leaches during the OER ${ }^{15}$, making the catalyst energy inefficient. 
In this work, we are developing a $\mathrm{NiOx}$ based catalyst by doping it with iron. Iron improves the electronic factor of $\mathrm{NiOx}{ }^{7,8,16,17}$ and we want to develop a simple synthesis method, it should be noted that this material has been successfully synthesized by electrodeposition by other authors ${ }^{12,15,16,18}$, however we have used a different plating bath, most publications have used nitrate based solutions, and we have used a Watts bath ${ }^{19}$. The advantage of using a Watts bath is that it is a commercial solution, the infrastructure to make this material on a high scale would be much easier to achieve.

We have previously worked with Raney $\mathrm{NiO}_{\mathrm{x}}{ }^{20}$, where $\mathrm{NiOx} \beta / \beta$ phases were grown by cyclic voltammetry. In that work $^{20}$, we explained how to identify $\mathrm{NiOx} \beta / \beta$ phases by cyclic voltammetry and Raman spectroscopy, the OER reaction mechanism found on this material, its stability and the model employed to fit EIS data, where, we used the Randles circuit.

Different authors ${ }^{12,16,18}$ have used iron salts in the range of 16 to $5 \mathrm{mM}$ to synthesize FeNiOx catalysts. They all use customized plating solutions and we have employed a different plating solution (i.e. Watts bath) that to the best of our knowledge has not been reported with the purpose of making NiOx based catalysts. We test iron salts in a range up to $150 \mathrm{mM}$.

In addition, we tried to understand the origin of the catalytic activity of NiOx based catalysts for the OER. It has been explained that in the region of $800-1150 \mathrm{~cm}^{-1}$, Raman peaks are observed and considered to be related to "active oxygen" in the oxyhydroxide structure ${ }^{17}$. We performed Raman tests to identify similar structures and support our results. In general, it is well agreed within the community that $\mathrm{NiOx} \beta / \beta$ phases are the source of the catalytic activity found in $\mathrm{NiOx}$ based catalysts ${ }^{8,10,12,21}$.

How iron promotes the OER activity on $\mathrm{NiOx}$ is still under debate ${ }^{14,22-27}$, including recent research supporting that $\gamma-\mathrm{NiOx}$ is the active phase ${ }^{23,24}$, instead of the conception that it is the $\beta$ - 
phase $^{14,25-27}$. Does iron a) make a mixed iron-nickel active site; b) induce the formation of a particular phase; c) iron is essential in the new active phase; d) modify the double layer. Although we incline for iron being incorporated into the active OER phase which acts as a bimetallic site. The best approach to determine what is the reason of FeNiOx base catalyst activity is by in situ operando techniques (i.e. Raman and X-ray absorption near edge structure $(\mathrm{XANES})^{23}$ ) and research is being done in that direction ${ }^{23}$.

The $\beta$-phase is related to stronger bonds with OER intermediates whereas the $\gamma$-phase has weaker bonds, this is the main reason that the $\gamma$-phase is thought to be the active phase as weaker bonds could be closer to an intermediate bond strength where catalysts operate efficiently. In the Raman spectra, the ratio of the two Raman peaks relates to $\beta / \gamma$ composition, making it difficult to deconvolute the catalytic mechanism. In addition, $\beta / \gamma-\mathrm{NiOx}$ phases show ${ }^{28-30}$; identical local bonding structure, similar voltametric behaviour, reversible interconversion and XPS data shows $\mathrm{Ni}(\mathrm{IV})$ in these two $\beta / \gamma \mathrm{NiOx}$ phases. Nickel (IV) is considered to be essential for OER activity. In the supporting information file, there is an explanation on the importance of $\mathrm{Ni}(\mathrm{IV})$ in the reaction mechanism of the OER.

\section{Materials and methods}

\section{Electrocatalyst preparation}

Nickel inserts of $5.00 \mathrm{~mm}$ of diameter and $99.0 \%$ of purity were made from a $\mathrm{Ni}$ rod acquired from Godfellow, these inserts were used as substrates for the catalysts (i.e. FeNiOx samples). The Ni insert surfaces were cleaned before electrodeposition. The cleaning procedure consisted of polishing with emory paper from high roughness numbers to smaller ones and as the last step, $3 \mu \mathrm{m}$ Alumina paste was employed to give a mirror like finishing. After polishing, the 
$\mathrm{Ni}$ inserts were degreased by 3 min sonication in the following sequence milli-Q water, acetone, isopropanol and milli-Q water.

The Ni inserts were used as rotating disk electrodes (RDE) to be plated with Ni from a Watts bath and doped with iron. The plating solution consisted of Nickel(II) sulfate hexahydrate (350 $\left.\mathrm{g} \mathrm{L}^{-1}\right)$, Nickel(II) chloride hexahydrate $\left(45 \mathrm{~g} \mathrm{~L}^{-1}\right)$ and Boric acid $\left(30 \mathrm{~g} \mathrm{~L}^{-1}\right)$ in milli-Q water. Iron(II) sulfate heptahydrate with the concentrations of 0.0 (sample 0$), 1.5 \mathrm{mM}$ (sample 1), 8.25 mM (sample 2), $16.5 \mathrm{mM}$ (sample 3), $90.0 \mathrm{mM}$ (sample 4) and 166.5 mM (sample 5) was added in the Watts bath solution.

The conditions of the plating were a bath temperature of $55^{\circ} \mathrm{C}$, a Ni rod as counter electrode (CE), RDE rotation speed of $400 \mathrm{rpm}$ and a current density of $-30 \mathrm{~mA} \mathrm{~cm} \mathrm{cor}^{-2}$ for minutes. After electrodeposition the RDE samples were stored in ziplock bags purged with argon.

\section{OER performance by linear voltammetry $(L V)$ and phase tracking}

Electrochemical tests were done with a Nordic Electrochemistry potentiostat/galvanostat model ECi-200 and a custom made Teflon cell ${ }^{31}$ (including an inbuilt Luggin). A three electrode configuration was employed for LV voltammograms. The samples 0 to 5 were the working electrodes (WE), a $\mathrm{Ni}$ rod was used as $\mathrm{CE}$ and a saturated $\mathrm{KCl} \mathrm{Ag} / \mathrm{AgCl}$ electrode as the reference electrode (RE). IR drop was corrected by Positive Feedback iR Compensation (only for $\mathrm{LV}$ and $\mathrm{CV}$ ). All tests were done at laboratory temperature $25^{\circ} \mathrm{C}$ in $1 \mathrm{M} \mathrm{NaOH}$ pre-purged with oxygen for 20 minutes and continuous bubbling at a lower gas rate. Linear voltammograms were obtained by steps of $5 \mathrm{mV}$ held for 1 minute from 470 to $505 \mathrm{mV}$ vs the RE, the RDE was kept at $3000 \mathrm{rpm}$. 
Cyclic voltammetry was used to track the phases of $\mathrm{NiO}_{x}$. The potential range was from 42 to $500 \mathrm{mV}$ vs the RE, the scan rate was $10 \mathrm{mV} \mathrm{s}^{-1}$ and the RDE was kept at $400 \mathrm{rpm}$.

\section{Electrochemical impedance spectroscopy (EIS) and Galvanostatic stability (GSS) of the OER}

Impedance spectra were obtained after a stabilization time of $30 \mathrm{~s}$ of the potential and the $\mathrm{RDE}$ was kept at $3000 \mathrm{rpm}$. The frequency range was from 0.2 to $150 \mathrm{~Hz}$ to cover the OER region with wave potential amplitude of $5 \mathrm{mV}$. The measured potential (i.e. Potentio-EIS) was such that the current density obtained was in the vicinity of $10 \mathrm{~mA} \mathrm{~cm}^{-2}$. GSS was performed in sequence after EIS, under current control, where, the current density was held at $10 \mathrm{~mA} \mathrm{~cm}{ }^{-2}$ for 20 minutes.

\section{Physical catalyst characterization}

Morphology and elemental composition of the surface of the samples were determined by scanning electron microscopy (SEM) employing a Hitachi S-3000N SEM equipped with energydispersive X-ray spectroscopy (EDS) model Thermo Scientific 606K-1SPS. Chemical phases were analyzed by by ex-situ Raman spectroscopy of the samples wetted with $1 \mathrm{M} \mathrm{NaOH}$ to mimic the conditions at open circuit potential. A red Raman laser was used (wavelength 632.817 $\mathrm{nm}, \mathrm{HR} 800$ ), the power was adjusted to $3 \mathrm{~mW}$.

\section{Surface elemental analysis by wet chemistry}

The iron and nickel mass concentration of the samples were determined by titration and oxygen by difference. The samples after electrodeposition were dried at $100{ }^{\circ} \mathrm{C}$ in air for one hour. The electrodeposited thin film was dissolved in aqua regia at $60{ }^{\circ} \mathrm{C}$ for $30 \mathrm{~min}$. The 
solution containing the dissolved metals was treated with ammonia to precipitate out the iron. The precipitate was separated from the liquid by filtration.

The precipitate was dissolved in $1 \mathrm{M} \mathrm{HCl}$ and $\mathrm{pH}$ adjusted by $2 \mathrm{M} \mathrm{NaOH}$ to the 1 to 1.5 range of $\mathrm{pH}$. Na-acetate was added to reach a $\mathrm{pH}$ of 2.5. Iron was titrated with Tiron as the color indicator and EDTA as the titrant. Ni was titrated with murexid as the color indicator and EDTA as the titrant.

\section{Results and discussions}

\section{Tafel plots, phase tracking and operational stability}

The Tafel slope $(\beta)$ of the samples 0 to 4 are shown in Fig 1 . The slope for the sample 4 is $68 \mathrm{mV} \mathrm{dec}^{-1}$ and its overpotential at $10 \mathrm{~mA} \mathrm{~cm}^{-2}\left(\eta_{10}\right)$ is $254 \mathrm{mV}$. This overpotential is close to that of the best materials found ${ }^{32}$ for alkaline OER at $10 \mathrm{~mA} \mathrm{~cm}{ }^{-2}$. The overpotential of the sample 4 is better than that of the Raney $\mathrm{NiO}_{x}$ developed by us ${ }^{20}$ by about $50 \mathrm{mV}$. This result supports the working hypothesis that iron doping does improve the energy efficiency of $\mathrm{NiO}_{\mathrm{x}}$ based catalysts for the OER. The linear voltammograms of the control sample (0) and samples 1 to 3 show that these samples are substantially less active than sample 4 . The voltammogram of the sample 5 is not included because this sample is too brittle and poorly adhered to the $\mathrm{Ni}$ substrate. These results made us focus on the sample 4 for the rest of the tests because the other samples are poor in terms of OER activity.

Fig 2 shows the $\mathrm{CV}$ of the samples 0 to 4 . It can be seen that the sample 4 has a substantial increment of the $\mathrm{NiO}_{\mathrm{x}} \beta / \beta$ phases. These phases are believed to be active for the OER. In the supporting information file there is an explanation on the origin of the catalytic activity found in the sample 4 . The shift of the NiOx redox peaks towards higher values supports 
the presence of a $\mathrm{Ni}(\mathrm{IV})$ phase that would make favorable the formation of peroxides and superoxides in the sample 4. The substantial increase of the electric current of the NiOx redox peaks indicates that a different phase of $\mathrm{NiOx}$ is formed, one that kinetically speaking can store more electric charge and have a $+3 \rightarrow+4$ nickel oxidation change in the sample 4 . Fig 3 shows the operational stability of the sample 4 . It can be seen that after 20 minutes, the activity of the sample for the OER is essentially the same. This result supports the idea that the reaction happening on the sample is only OER as after 20 minutes it should have shown signs of deterioration.

\section{Electrochemical impedance spectroscopy}

The charge transfer resistance $\left(R_{\mathrm{ct}}\right)$ determined at $10 \mathrm{~mA} \mathrm{~cm}{ }^{-2}$ for the sample 4 is $1.80 \Omega$ $\mathrm{cm}^{2}$ and our previous work ${ }^{20}$ on Raney $\mathrm{NiO}_{\mathrm{x}}$ yielded $3.28 \Omega \mathrm{cm}^{2}$ at the same conditions. This test substantiates that iron doping improves the OER efficiency of $\mathrm{NiO}_{\mathrm{x}}$ based catalyst. The roughness factor determined at $10 \mathrm{~mA} \mathrm{~cm}^{-2}$ for the sample 4 is 2775 , which is bellow to that of Raney $\mathrm{NiO}_{\mathrm{x}}{ }^{20}$ of 3041 .

The Bode impedance of the sample 4 (i.e. Fig 4 (b)) and that from Raney $\mathrm{NiO}_{\mathrm{x}}{ }^{20}$ have a minimum of the phase $(\mathrm{Z})$ at different frequencies. Raney $\mathrm{NiO}_{\mathrm{x}}{ }^{20}$ minima is at about $10 \mathrm{~Hz}$, whereas the sample 4 is at about $2 \mathrm{~Hz}$. This finding suggests that the coverage on sample 4 is different than Raney $\mathrm{NiO}_{x}$, meaning that a different reaction mechanism is expected to happen on the sample 4. Alternatively, the binding energy of the adsorbed specie on the sample 4 could be closer to an intermediate value because of the minima lower frequency (i.e. lower binding energy) in the Bode diagram. Intermediate binding energies, between the adsorbed specie and the catalyst, are key variables in the design of catalysts. Lower binding energies makes the adsorbate 
more physisorbed like, this is a more reversible reaction, more spontaneous. This result supports why the sample 4 is energy efficient towards the OER.

\section{Raman spectroscopy}

As explained in the introduction, we tried to elucidate the origin of the activity found on the sample 4. This sample is substantially better that the developed Raney $\mathrm{NiO}_{\mathrm{x}}{ }^{20}$ by us. In this respect, a peak in the Raman spectrum of the sample 4 shown in Fig 5 in the region between 1000 and $1200 \mathrm{~cm}^{-1}$ was found. This peak is believed to be related to the activity of the sample 4, Diaz-Morales ${ }^{17}$ explains that a peak in the region of $800-1150 \mathrm{~cm}^{-1}$ is considered "active oxygen". Considering this result and those from CV and EIS, it is concluded that iron doping improves the OER efficiency of NiOx.

In addition, the peaks in the Raman shift of 476 and $555 \mathrm{~cm}^{-1}$, are typical of $\beta / \gamma \mathrm{NiOx}$.

The ratio between the intensity of these peaks is believed to be related to the relative composition of the $\beta$-and $\gamma$-phases. The $\beta$-phase makes stronger bonds because it is a more closely packed structure than the disordered $\gamma$-phase and the average valency of nickel is about 3 and 3.7 in the $\beta$-and $\gamma$ - phases, respectively. Higher valency promotes water oxidation. In the introduction it was explained that the OER mechanism on NiOx is still under debate, however, when comparing the Raman spectra from Fig 5 to that of our previous publication ${ }^{20}$, the $\beta / \gamma \mathrm{NiOx}$ peaks have shifted to lower Raman shift values, this indicates that the composition of the $\gamma$ - phase is higher. This makes us conclude that the sample 4 has a high concentration of the $\gamma$ - phase which makes it be highly active for the OER. 


\section{Micrographs and elemental analysis by SEM / SEM EDS and wet chemistry}

The micrographs on Fig 6 show that all the samples 1 to 4 are rough, and samples 1 and 4. Samples 2 and 3 have about two particle sizes (i.e. bimodal), uniformly distributed. These results are in agreement to those found by EIS. The sample 4 has a relatively high roughness factor by EIS and its micrograph shows its surface to be rough.

In our previous work with Raney $\mathrm{NiO}_{\mathrm{x}}{ }^{20}$, a percentage by mass of $7.59 \%$ of oxygen was present on the surface and the rest was $91.32 \%$ of $\mathrm{Ni}$ and the difference belonging to aluminum and iron $(0.40 \%$ and $0.68 \%$, respectively). Table 1 shows that in all the samples, the amount of oxygen is always smaller than that of iron or nickel. The sample 4 being the one of interest, shows a combination of iron to nickel at about $1: 2$ by mass (SEM EDX spectrum shown in the Fig SI2). This result is supported by wet chemistry analysis that roughly yielded a 1:2 ratio, the results were $48.56 \%, 27.01 \%$ for $\mathrm{Ni}$ and $\mathrm{Fe}$, respectively, and oxygen by difference at $24.43 \%$.

\section{Conclusions}

We have found that iron doping for $\mathrm{NiO}_{x}$ based catalyst can be done electrochemically and iron improves the energy efficiency of $\mathrm{NiO}_{\mathrm{x}}$ for alkaline OER. The developed sample 4 shows competitive OER activity similar to those of the best samples found in the field. We believe that the origin of the activity found in the sample 4 is related to the concentration of active sites that are "active oxygen" and a high concentration of $\gamma$-NiOx.

Finally, we believe that this research could assist developing better combinations of $\mathrm{NiO}_{\mathrm{x}}$ based catalyst. Iron doping in this material, leaches into the electrolyte during operation. Finding new alternatives to synthesize ${ }^{33}$ this material could make ternary combinations such as $\mathrm{Fe}, \mathrm{Ni}$ 
and $\mathrm{Cr}$, be stable during electrolytic operation. In addition, gold as a substrate could improve the efficiency of $\mathrm{NiO}_{\mathrm{x}}$ based catalyst.

\section{Acknowledgements}

The authors would like to thank the financial support given by the Australian department of education with its Endeavour program with the grant number 6880/2018.

\section{Additional Information}

There is NO Competing Interest.

\section{References}

1 Beale, C. in Independent (independent, London, 2017).

2 Delgado, D., Hefter, G. \& Minakshi, M. in Alternative Energies: Updates on Progress (ed Germán Ferreira) 141-161 (Springer Berlin Heidelberg, 2013).

3 Hamilton-Smith, L. in $A B C$ news (ABC, Australia, 2018).

4 Dudley, D. in Forbes (Forbes Media LLC, US, 2018).

5 Delgado, D., Minakshi, M., Senanayake, G. \& Kim, D.-J. Modified electrolytic manganese dioxide (MEMD) for oxygen generation in alkaline medium. J. Solid State Electrochem. 19, 1133-1142, doi:10.1007/s10008-014-2727-1 (2015).

6 Delgado, D., Minakshi, M., McGinnity, J. \& Kim, D.-J. Co/Mo bimetallic addition to electrolytic manganese dioxide for oxygen generation in acid medium. Sci. Rep. 5, 15208, doi:10.1038/srep15208 (2015).

7 Shin, H., Xiao, H. \& Goddard, W. A. In Silico Discovery of New Dopants for Fe-Doped Ni Oxyhydroxide (Ni1-xFexOOH) Catalysts for Oxygen Evolution Reaction. Journal of the American Chemical Society 140, 6745-6748, doi:10.1021/jacs.8b02225 (2018).

8 Fidelsky, V. \& Toroker, M. C. Enhanced Water Oxidation Catalysis of Nickel Oxyhydroxide through the Addition of Vacancies. The Journal of Physical Chemistry C 120, 25405-25410, doi:10.1021/acs.jpcc.6b07931 (2016).

9 Godwin, I. J. \& Lyons, M. E. G. Enhanced oxygen evolution at hydrous nickel oxide electrodes via electrochemical ageing in alkaline solution. Electrochemistry Communications 32, 39-42, doi:https://doi.org/10.1016/j.elecom.2013.03.040 (2013).

10 Yeo, B. S. \& Bell, A. T. In Situ Raman Study of Nickel Oxide and Gold-Supported Nickel Oxide Catalysts for the Electrochemical Evolution of Oxygen. The Journal of Physical Chemistry C 116, 8394-8400, doi:10.1021/jp3007415 (2012).

11 C., M. I. et al. Universality in Oxygen Evolution Electrocatalysis on Oxide Surfaces. ChemCatChem 3, 1159-1165, doi:doi:10.1002/cctc.201000397 (2011).

12 Corrigan, D. A. \& Bendert, R. M. Effect of Coprecipitated Metal Ions on the Electrochemistry of Nickel Hydroxide Thin Films: Cyclic Voltammetry in 
1M KOH Journal of The Electrochemical Society 136, 723-728, doi:10.1149/1.2096717 (1989).

13 Hall, D. E. Ni(OH)2 Impregnated Anodes for Alkaline Water Electrolysis. Journal of The Electrochemical Society 130, 317-321, doi:10.1149/1.2119702 (1983).

14 Bode, H., Dehmelt, K. \& Witte, J. Zur kenntnis der nickelhydroxidelektrode-I.Über das nickel (II)-hydroxidhydrat. Electrochimica Acta 11, 1079-IN1071, doi:https://doi.org/10.1016/0013-4686(66)80045-2 (1966).

15 Speck, F. D. et al. On the Electrolytic Stability of Iron-Nickel Oxides. Chem 2, 590-597, doi:https://doi.org/10.1016/j.chempr.2017.03.006 (2017).

16 Chakthranont, P. et al. Effects of Gold Substrates on the Intrinsic and Extrinsic Activity of High-Loading Nickel-Based Oxyhydroxide Oxygen Evolution Catalysts. ACS Catalysis 7, 5399-5409, doi:10.1021/acscatal.7b01070 (2017).

17 Diaz-Morales, O., Ferrus-Suspedra, D. \& Koper, M. T. M. The importance of nickel oxyhydroxide deprotonation on its activity towards electrochemical water oxidation. Chemical Science 7, 2639-2645, doi:10.1039/C5SC04486C (2016).

18 McCrory, C. C. L., Jung, S., Peters, J. C. \& Jaramillo, T. F. Benchmarking Heterogeneous Electrocatalysts for the Oxygen Evolution Reaction. Journal of the American Chemical Society 135, 16977-16987, doi:10.1021/ja407115p (2013).

19 ASM Handbook. Properties and Selection: Nonferrous Alloys and Special-Purpose Materials. Vol. 2 (ASM International, 1990).

20 Delgado, D., Bizzotto, F., Zana, A. \& Arenz, M. Accelerated durability test for high surface area oxyhydroxide nickel (NiOx) supported on Raney Nickel as catalyst for the alkaline oxygen evolution reaction. ChemPhysChem 0, doi:10.1002/cphc.201900195 (2019).

21 Lyons, M. E. G. \& Brandon, M. P. The Oxygen Evolution Reaction on Passive Oxide Covered Transition Metal Electrodes in Aqueous Alkaline Solution. Part 1-Nickel. Int. J. Electrochem. Sci. 3, 1386-1424 (2008).

22 Xiao, H., Shin, H. \& Goddard, W. A. Synergy between Fe and Ni in the optimal performance of $(\mathrm{Ni}, \mathrm{Fe}) \mathrm{OOH}$ catalysts for the oxygen evolution reaction. Proceedings of the National Academy of Sciences 115, 5872-5877, doi:10.1073/pnas.1722034115 (2018).

23 Bediako, D. K. et al. Structure-Activity Correlations in a Nickel-Borate Oxygen Evolution Catalyst. Journal of the American Chemical Society 134, 6801-6809, doi:10.1021/ja301018q (2012).

24 Corrigan, D. A. \& Knight, S. L. Electrochemical and Spectroscopic Evidence on the Participation of Quadrivalent Nickel in the Nickel Hydroxide Redox Reaction. Journal of The Electrochemical Society 136, 613-619, doi:10.1149/1.2096697 (1989).

25 Louie, M. W. \& Bell, A. T. An Investigation of Thin-Film Ni-Fe Oxide Catalysts for the Electrochemical Evolution of Oxygen. Journal of the American Chemical Society 135, 12329-12337, doi:10.1021/ja405351s (2013).

26 Doyle, R. L. \& Lyons, M. E. G. Kinetics and Mechanistic Aspects of the Oxygen Evolution Reaction at Hydrous Iron Oxide Films in Base. Journal of The Electrochemical Society 160, H142-H154, doi:10.1149/2.015303jes (2013).

27 Lyons, M. E. G., Doyle, R. L., Godwin, I., O’Brien, M. \& Russell, L. Hydrous Nickel Oxide: Redox Switching and the Oxygen Evolution Reaction in Aqueous Alkaline 
Solution. Journal of The Electrochemical Society 159, H932-H944, doi:10.1149/2.078212jes (2012).

28 Biesinger, M. C., Payne, B. P., Lau, L. W. M., Gerson, A. \& Smart, R. S. C. X-ray photoelectron spectroscopic chemical state quantification of mixed nickel metal, oxide and hydroxide systems. Surface and Interface Analysis 41, 324-332, doi:10.1002/sia.3026 (2009).

29 Wehrens-Dijksma, M. \& Notten, P. H. L. Electrochemical Quartz Microbalance characterization of $\mathrm{Ni}(\mathrm{OH}) 2$-based thin film electrodes. Electrochimica Acta 51, 36093621, doi:https://doi.org/10.1016/j.electacta.2005.10.022 (2006).

30 Mansour, A. N. \& Melendres, C. A. Characterization of KNiIO6 by XPS. Surface Science Spectra 3, 287-295, doi:10.1116/1.1247758 (1994).

31 Mayrhofer, K. J. J., Crampton, A. S., Wiberg, G. K. H. \& Arenz, M. Analysis of the Impact of Individual Glass Constituents on Electrocatalysis on Pt Electrodes in Alkaline Solution. Journal of The Electrochemical Society 155, P78-P81, doi:10.1149/1.2904882 (2008).

32 Seh, Z. W. et al. Combining theory and experiment in electrocatalysis: Insights into materials design. Science 355, doi:10.1126/science.aad4998 (2017).

33 Delgado, D. Nanosynthesis of nickel oxyhydroxide alloys for alkaline oxygen evolution. Researchgate.com, doi:10.13140/RG.2.2.32136.26887 (2019). 


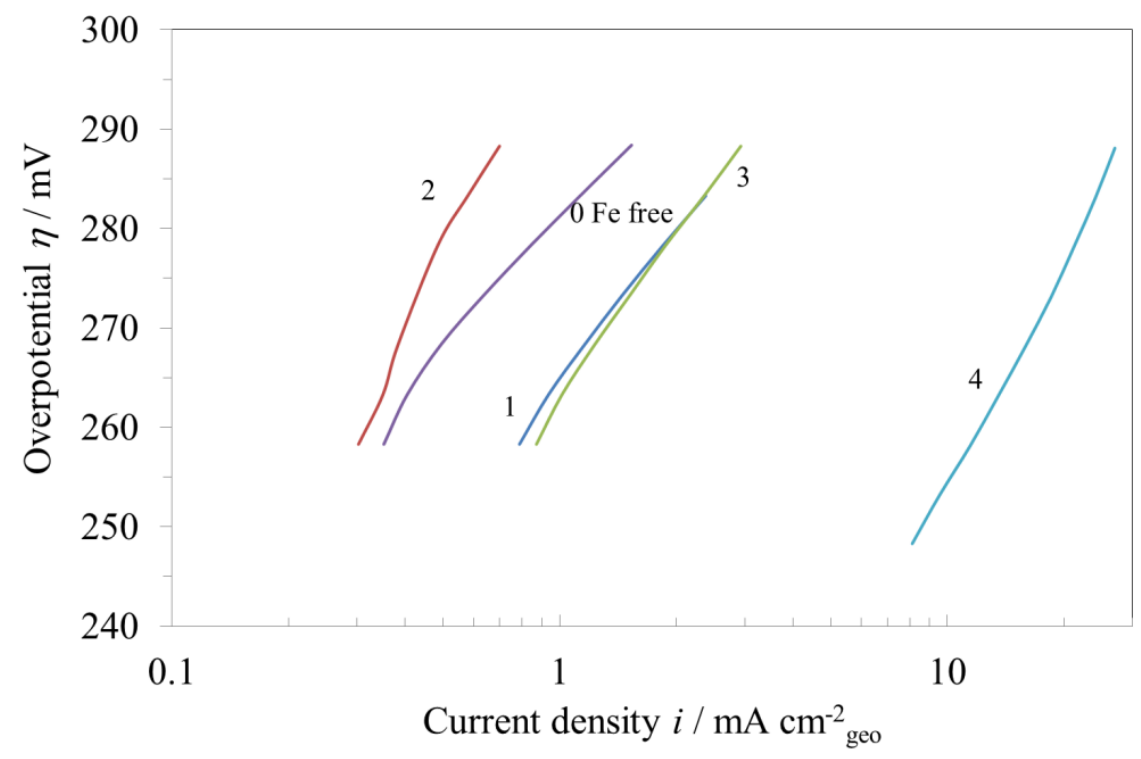

Figure 1 Tafel plot of the FeNiOx samples 0 to 4 in $1 \mathrm{M} \mathrm{NaOH}$ solution.

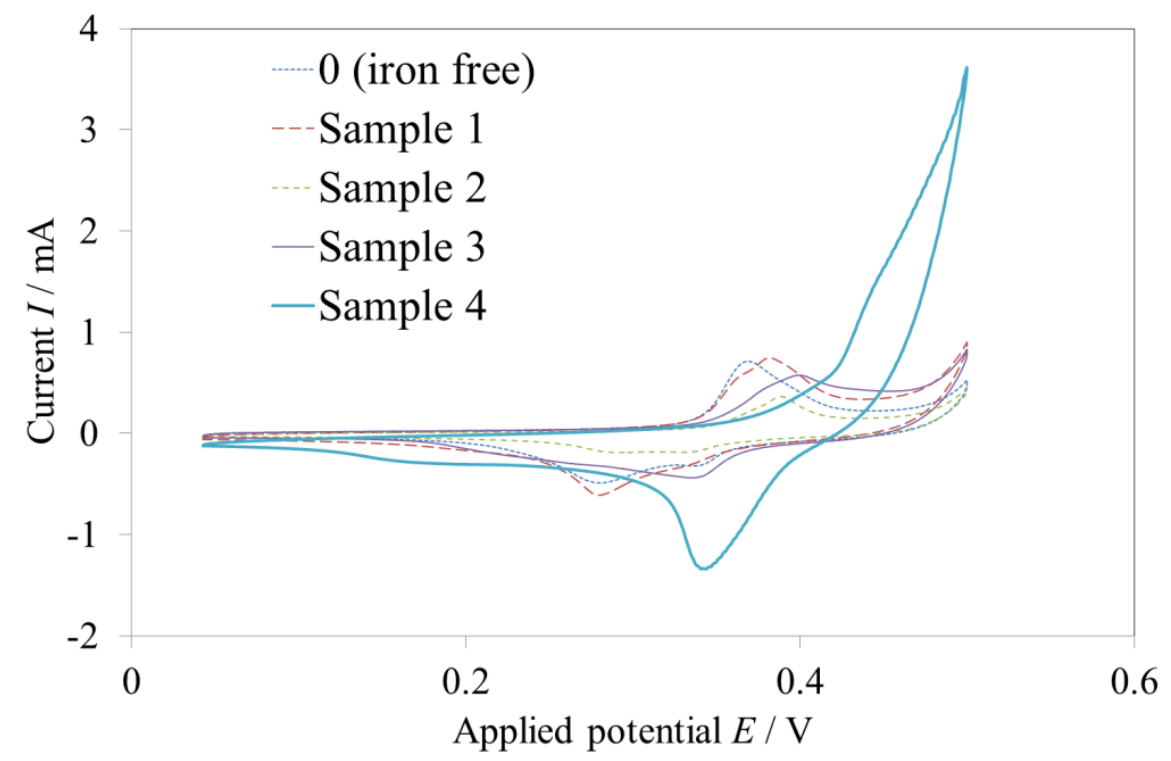

Figure 2 Cyclic Voltammograms of the synthesized NiOx samples. 


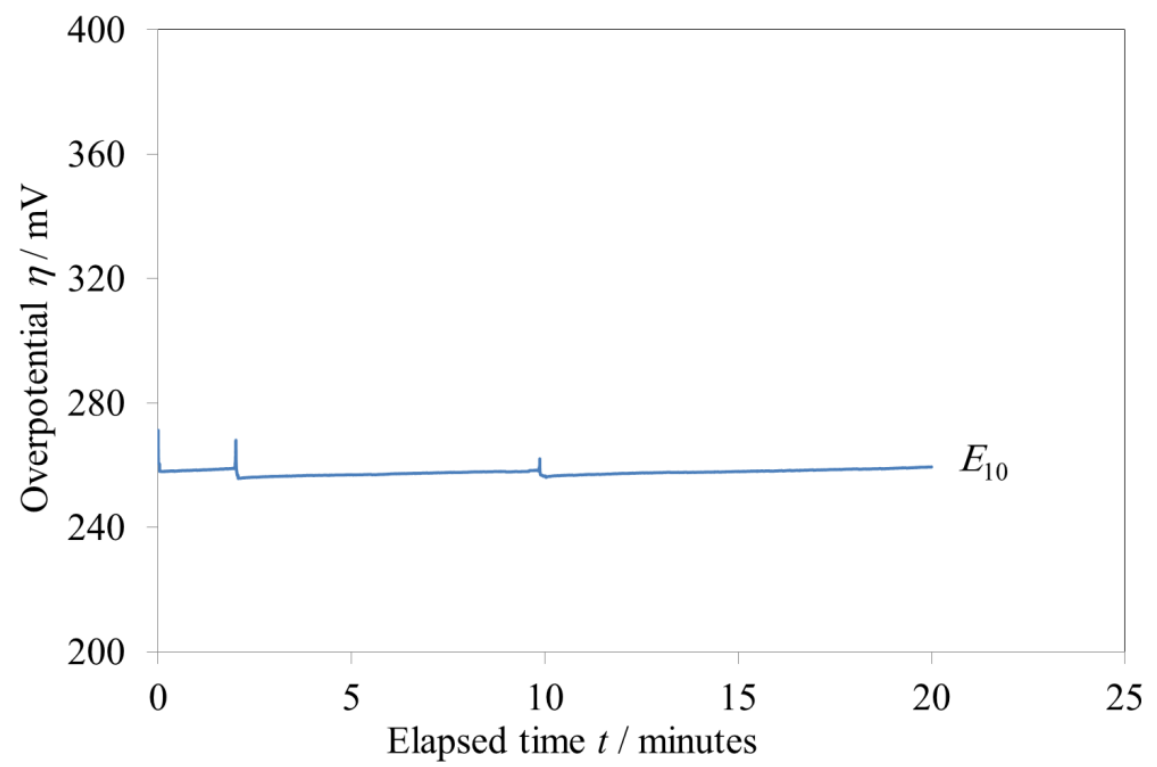

Figure 3 Galvanostatic test for 20 minutes of the FeNiOx sample 4 in $1 \mathrm{M} \mathrm{NaOH}$ solution.
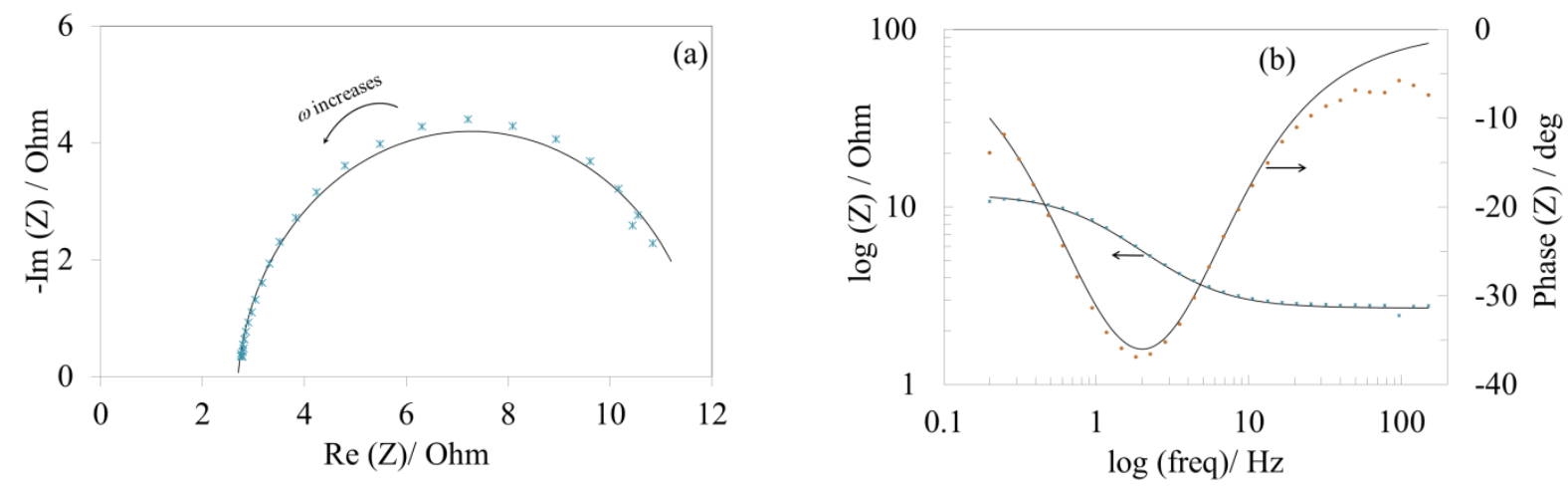

Figure 4 Electrochemical impedance spectrum of the $\mathrm{FeNiO}_{x}$ sample 4 at $480 \mathrm{mV}$ vs $\mathrm{Ag} / \mathrm{AgCl}$ $\left(\approx 10 \mathrm{~mA} \mathrm{~cm}{ }^{-2}\right.$ ), symbols as experimental data, solid lines as model fit. Nyquist (a) and Bode impedance (b). 


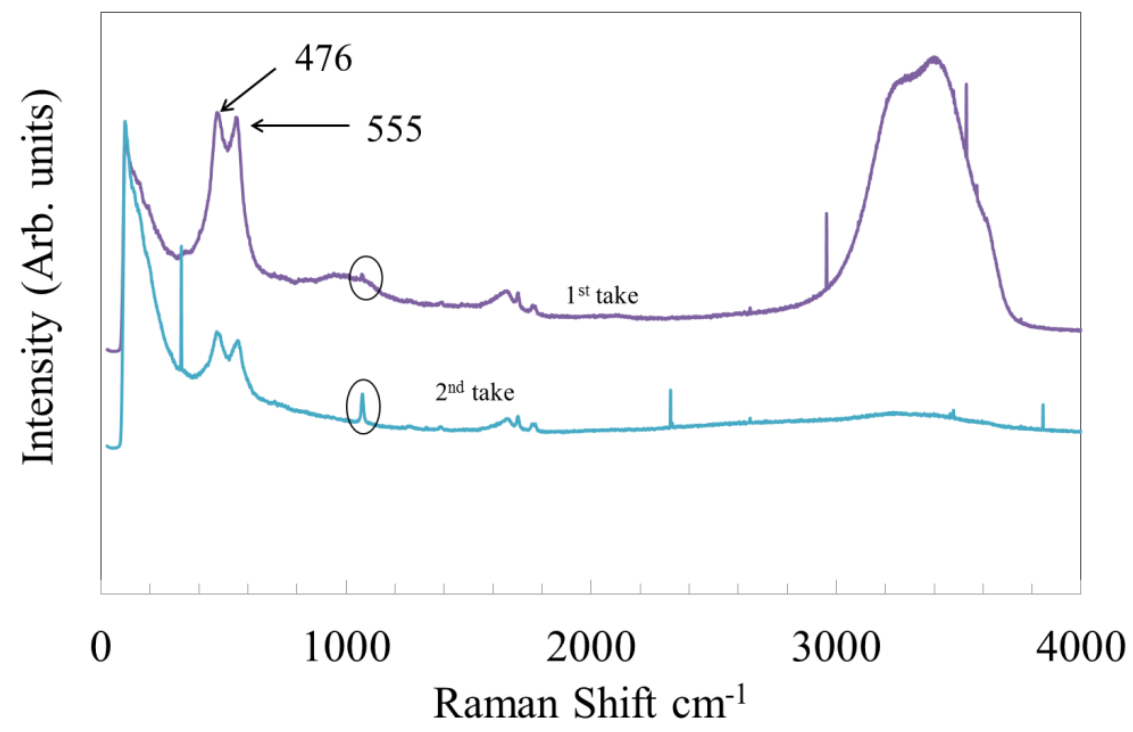

Figure 5 Raman spectra of the sample 4 at open potential. The spectrum was measured two times, shown as $1^{\text {st }}$ and $2^{\text {nd }}$ take. 

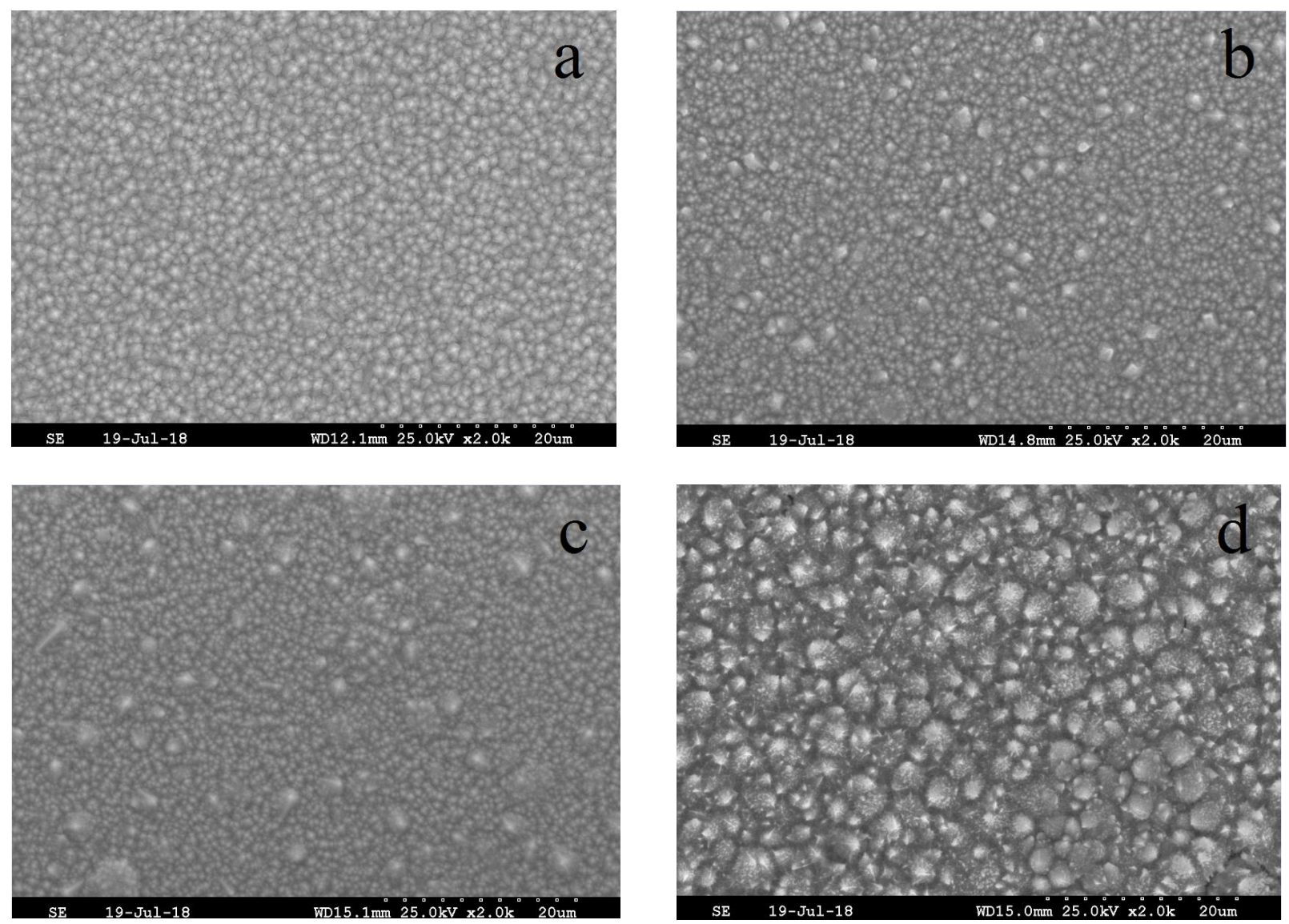

Figure 6 Surface morphology by SEM for the samples 1 to 4 in order as (a) to (d). 
Table $1 \mathrm{Ni}, \mathrm{Fe}$ and $\mathrm{O}$ elemental dispersive analysis of the $\mathrm{FeNiO}_{\mathrm{x}}$ electrodes.

\begin{tabular}{crrrr}
\hline Concentration & \multicolumn{4}{c}{ FeNiOx sample ID } \\
\cline { 2 - 5 } by mass (\%) & $\mathbf{1}$ & $\mathbf{2}$ & $\mathbf{3}$ & $\mathbf{4}$ \\
\hline $\mathrm{Fe}$ & 7.22 & 8.32 & 11.84 & 33.47 \\
\hline $\mathrm{Ni}$ & 91.06 & 86.96 & 83.16 & 63.27 \\
\hline $\mathrm{O}$ & 1.72 & 4.71 & 4.99 & 3.38 \\
\hline
\end{tabular}

